\title{
Use of the Dynamic External Distractor Ligamentotaxor in finger trauma
}

\author{
Michel Schoofs
}

From 10th Congress of the Asia-Pacific Federation of Societies of Surgery fo the Hand and the 6th Congress of Asia-Pacific Federation of Societies of Hand Therapists

Kuala Lumpur, Malaysia. 2-4 October 2014

\section{Introduction}

The treatment of fracture dislocations of the fingers is difficult.

The concept of capsuloligamentotaxis is familiar but the systems of external distraction are cumbersome.

The Suzuki system is ingenious but not devoid of complications.

\section{Materials}

We report results of a series of 35 fingers in 32 patients treated by the Ligamentotaxor ${ }^{\circledR}$ external distraction system.

\section{Results}

Twenty-five patients were operated in emergency following complex MCP, PIP and DIP fractures and 7 patients at more than one month following trauma due to neglected dislocation or complications of arthroplasty.

The duration of distraction was 6 weeks.

Associated osteosynthesis was performed in 3 cases.

The mean follow-up was 36 months.

Grip strength was $85 \%$ of the contralateral side.

Active flexion was $75^{\circ}$ and flexion deformity $20^{\circ}$.

Pain recorded using the VAS was 1.5 and quick DASH score was 17.

One patient had sepsis requiring premature removal of metalwork.

One patient disassembled the distraction system himself.

Bone union occurred in all cases.

\section{Conclusions}

Despite the imperfections of the results, we think that Ligamentotaxor $^{\circledR}$ is not cumbersome, easy to assemble

SOS Main Lille, Lesquin, 59810 France

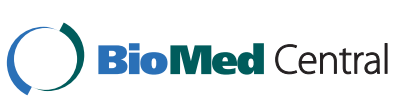

(0) 2015 Schoofs; licensee BioMed Central Ltd. This is an Open Access article distributed under the terms of the Creative Commons Attribution License (http://creativecommons.org/licenses/by/4.0), which permits unrestricted use, distribution, and reproduction in any medium, provided the original work is properly cited. The Creative Commons Public Domain Dedication waiver (http:// creativecommons.org/publicdomain/zero/1.0/) applies to the data made available in this article, unless otherwise stated. 